\title{
Challenges in comprehensive management of spinal cord injury in India and in the Asian Spinal Cord network region: findings of a survey of experts, patients and consumers
}

\author{
HS Chhabra $^{1}$, S Sharma ${ }^{2}$ and M Arora ${ }^{2,3}$
}

\section{Study design: Online survey.}

Objectives: To understand the prevailing scenario of the comprehensive management of spinal cord injuries (SCI) in India and in the Asian Spinal Cord Network (ASCoN) region, especially with a view to document the challenges faced and its impact.

Setting: Indian Spinal Injuries Centre.

Methods: A questionnaire was designed which covered various aspects of $\mathrm{SCl}$ management. Patients, consumers (spinal injured patients discharged since at least 1 year) and experts in SCI management from different parts of India and the ASCoN region were approached to complete the survey.

Results: Sixty patients, 66 consumers and 34 experts completed the survey. Difference of opinion was noticed among the three groups. Disposable Nelaton catheters were used by $57 \%$ consumers and $47 \%$ patients. For reusable catheter, $31 \%$ experts recommended processing with soap and running water and $45 \%$ recommended clean cotton cloth bag for storage. Pre-hospital care and community inclusion pose the biggest challenges in management of $\mathrm{SCl}$. More than $75 \%$ of $\mathrm{SCl}$ faced problems of access and mobility in the community. Awareness about SCl, illiteracy and inadequate patient education are the most important factors hindering pre- and in-hospital care. Inadequate physical as well as vocational rehabilitation and financial barriers are thought to be the major factors hindering integration of spinal injured into mainstream society. Strong family support helped in rehabilitation.

Conclusions: Our study brought out that $\mathrm{SCl}$ in India and $\mathrm{ASCoN}$ region face numerous challenges that affect access to almost all aspects of comprehensive management of SCl.

Spinal Cord (2018) 56, 71-77; doi:10.1038/sc.2017.102; published online 12 September 2017

\section{INTRODUCTION}

Management of spinal cord injury (SCI) was revolutionized during the second world war. ${ }^{1,2}$ The establishment of services for comprehensive SCI management and ongoing technological advancements has made improvement in outcomes and quality of life possible. However, numerous factors in low- and middle-income countries (LMIC) still pose a big challenge to SCI comprehensive management and inclusion in the community. ${ }^{3}$ Thus, a large number of SCI in LMIC are still deprived of the benefits of advancements of knowledge and technology available to their counterparts in high-income countries.

Moreover, there is often a substantial delay in initiating management. In a previous study, causes and overall consequences of delay in initiation of comprehensive management of SCI were studied. ${ }^{4}$ It was evident that the delay added to the complexity of management, resulted in a higher incidence of complications, longer hospitalization, added costs and adversely affected outcomes. ${ }^{4}$

Rathore et al. ${ }^{5}$ identified the challenges faced in traumatic SCI management in Pakistan. Others have investigated the challenges in individual components of SCI management like the inadequacy of pre-hospital care in LMIC. ${ }^{6}$ Scovil et al. ${ }^{7}$ highlighted inadequate community integration and health problems of spinal cord injured after discharge in Nepal. Chhabra et al. ${ }^{4}$ pointed out that the lack of infrastructure and trained manpower in India are important challenges. Hansen et al. ${ }^{8}$ brought out the challenges of vocational rehabilitation in Bangladesh.

Even though the challenges in comprehensive management of SCI are quite obvious in less-resourced settings, there is hardly any published literature on overall challenges for comprehensive management of SCI. Hence, we conducted this study in order to understand the prevailing scenario of comprehensive management of SCI in these less-resourced settings with a view to document the challenges and its impact. In order to get a comprehensive understanding, the patient's and consumer's perspective were also studied in addition to that of the experts. The term consumer has been used for people with spinal cord injury who have been discharged from the hospital since at least 1 year. The term expert has been used for people with specialized skills and knowledge in SCI management.

${ }^{1}$ Spine Service, Indian Spinal Injuries Centre, New Delhi, India; ${ }^{2}$ Research Department, Indian Spinal Injuries Centre, New Delhi, India and ${ }^{3}$ John Walsh Centre for Rehabilitation Research, Sydney Medical School - Northern, The University of Sydney, Sydney, NSW, Australia

The study had been presented as a poster in the Associations of Spine Surgeons of India session at Spine Week 2016 in Singapore. The same has been published as proceedings of the meeting in Asian Spine Journal. (Associations of Spine Surgeons of India 2016. Asian Spine J. 2016 Jun; 10(suppl 1): S1-S31).

Correspondence: Dr HS Chhabra, Spine Service, Indian Spinal Injuries Centre, New Delhi 110070, India.

E-mail: drhschhabra@isiconline.org

Received 22 September 2016; revised 1 July 2017; accepted 10 July 2017; published online 12 September 2017 


\section{METHODS}

A questionnaire was developed especially for this purpose. It covered various aspects of SCI management like pre-hospital care, acute care, comprehensive rehabilitation, bladder management, the availability of infrastructure, community inclusion, prevention, components posing challenge, factors hindering management and strengths of the society helping overcome the challenge.

The questionnaire for experts had 54 multiple choice questions in all. For 34 questions only one option could be chosen, whereas for 20 questions multiple options could be chosen. Thirty-four experts in SCI management from different parts of India and the Asian Spinal Cord Network (ASCoN) region were approached to participate in the survey.

Sixty patients from two Indian centers and 66 consumers from various parts of India were approached to participate in the survey and complete the modified versions of the same questionnaire containing 35 and 37 questions, respectively (see Supplementary Data for accessing the questionnaires). It was different than the one for consumers as it contained questions directed to patients regarding the injury and details regarding the pre-hospital, in-hospital and counseling facilities before discharge from the hospital. The questionnaire for patients explored the factors that play an important role in accessing management from the patient's perspective, including those that hindered acute management, surgical intervention, bladder management as well as prevention and management of complications during hospitalization. The questionnaire for consumers on the other hand also covered the perception of consumers regarding the factors hindering management of SCI, especially community inclusion and vocational rehabilitation. The data were analyzed separately for patients, consumers and experts, and presented as descriptive statistics.

\section{RESULTS}

Sixty patients, 66 consumers and 34 experts completed the survey. Thus, $75 \%$ patients, $83 \%$ consumers and $68 \%$ experts to whom the questionnaires were sent responded. Patients participated from two centers from India, consumers from 14 states of India and experts from 9 countries of the ASCoN region (including India) (see Table 1). The experts', patients' and consumers' opinions were almost similar with respect to availability of facilities including pre-hospital, acute and rehabilitation care for most of the aspects of SCI management (see Table 2). However, there was a difference of experts', patients' and consumers' opinions in availability of first-aid at-site, trained staff for evacuation, ventilator facilities, conduction of periodic meeting for assessment of achievements of goals and availability of vocational counseling.

Figure 1 depicts the experts' perspective of availability of disciplines involved in SCI management. Vocational counselors, peer counselors, sports counselors, social workers, trained staff for evacuation, orthotists, occupational therapists and psychologists were the disciplines least available in that order. Physicians, nurses, nurse aid/ward aide and physiotherapists were the disciplines generally available.

Experts', patients' and consumers' perspective on the availability of various facilities for physical, psychosocial, sexual, vocational rehabilitation, pre-discharge planning and follow-up is depicted in Figure 2.

Fifty-seven percent consumers and $47 \%$ patients used disposable Nelaton catheters (see Figure 3). Thirty-nine percent experts and 32\% consumers recommended processing of reusable catheters with soap and running water. Majority of experts (46\%) recommended a clean cotton cloth bag for storage of a catheter at home. While $77 \%$ experts suggested that concomitant medical therapy was administered for voiding dysfunction, only $23 \%$ patients claimed to have received it.

The patients and consumers identified awareness about SCI/ illiteracy/inadequate education as the most important factors hindering pre-hospital care. The same were also the most important factors hindering all aspects of management of SCI. Mind-set and social beliefs were identified as the least important factors in this regard (see Table 3).

According to the consumers' perspective, pre-hospital care and community inclusion are the two biggest challenges in the Indian setup (see Figure 4). The majority of consumers reported that access $(54 \%)$ and mobility (48\%) were the most common problems faced by more than $75 \%$ of people with SCI in the community.

Experts were of the opinion that inadequate vocational rehabilitation and financial barriers are the two most important factors that hinder the integration of people with SCI into mainstream society. These were followed by inadequate physical rehabilitation, problems of access in the workplace as well as the environment and lack of availability of assistive technology in that order of importance. The experts, patients and consumers unanimously pointed toward the strong family and spouse support as being the most positive factor that helped overcome the challenges (see Table 4).

\section{DISCUSSION}

The revolution of SCI management brought hope to a large number of people suffering from this devastating ailment. ${ }^{1}$ However, for quite a while the benefits of these advances in management were largely available in the high-income countries where numerous SCI centers

\section{Table 1 Geographical representation of patients, consumers and experts}

\begin{tabular}{|c|c|c|c|}
\hline Item & Patients & Consumers & Experts \\
\hline Number & 60 & 66 & 34 \\
\hline Inclusion criteria & Completion of in-hospital care & Discharged from hospital at least since 1 year & Dealing with $\mathrm{SCl}$ patients \\
\hline \multirow[t]{13}{*}{ Geographical regions - participants } & Indian Spinal Injuries Centre (ISIC) - 40 & Chandigarh - 2 & Bangladesh - 3 \\
\hline & All India Institute of Medical Sciences (AIIMS) - 20 & Gujarat - 4 & China - 1 \\
\hline & & Haryana - 6 & India - 15 \\
\hline & & Jharkhand - 2 & Malaysia - 1 \\
\hline & & Karnataka - 4 & Nepal - 7 \\
\hline & & Madhya Pradesh - 2 & Pakistan - 2 \\
\hline & & Maharashtra - 8 & Sri Lanka - 3 \\
\hline & & New Delhi - 16 & Thailand - 1 \\
\hline & & Punjab - 4 & Vietnam - 1 \\
\hline & & Telangana - 4 & \\
\hline & & Uttar Pradesh - 8 & \\
\hline & & Uttarakhand - 2 & \\
\hline & & West Bengal - 4 & \\
\hline
\end{tabular}


Table 2 Percentage of respondents declaring availability of various individual components of $\mathrm{SCl}$ management

\begin{tabular}{|c|c|c|c|}
\hline & Patient & Consumer & Expert \\
\hline \multicolumn{4}{|l|}{ Pre-hospital care } \\
\hline First-aid at-site & 10 & 13 & 42 \\
\hline Trained staff for evacuation & 3 & 6 & 70 \\
\hline $\begin{array}{l}\text { Two or more institutional transfer before reaching } \\
\text { definitive institution }\end{array}$ & 63 & 56 & 69 \\
\hline $\begin{array}{l}\text { Time taken to reach definitive institution more } \\
\text { than } 1 / 2 \text { months }\end{array}$ & 22 & 16 & 26 \\
\hline $\begin{array}{l}\text { Deterioration in neurological status while transfer } \\
\text { to definitive institution }\end{array}$ & 19 & 28 & 21 \\
\hline \multicolumn{4}{|l|}{ Acute hospital care } \\
\hline Acute management facilities for spinal cord injury & 33 & 32 & 40 \\
\hline Protocols for acute care & NA & NA & 8 \\
\hline Ventilator facilities & 40 & 52 & 84 \\
\hline Administration of anticoagulant prophylaxis & 47 & 45 & 45 \\
\hline \multicolumn{4}{|l|}{ Rehabilitation care } \\
\hline $\begin{array}{l}\text { Trained rehabilitation staff for management of } \\
\text { spinal cord injury }\end{array}$ & 42 & 32 & 53 \\
\hline $\begin{array}{l}\text { Initial assessment followed by goal planning for } \\
\text { treatment }\end{array}$ & 33 & 32 & 41 \\
\hline $\begin{array}{l}\text { Periodic meeting once weekly for assessment of } \\
\text { achievement of goals and progress }\end{array}$ & 18 & 31 & 30 \\
\hline $\begin{array}{l}\text { Periodic meeting once monthly for assessment of } \\
\text { achievement of goals and progress }\end{array}$ & 82 & 6 & 7 \\
\hline \multicolumn{4}{|l|}{ Sexual management } \\
\hline Sexual counseling for patients & 23 & 33 & 37 \\
\hline Sexual counseling for spouse & 12 & 22 & 10 \\
\hline $\begin{array}{l}\text { Educational material (video demonstration) for } \\
\text { sexual counseling }\end{array}$ & 13 & 19 & 5 \\
\hline Fertility clinic services & 3 & 4 & 8 \\
\hline \multicolumn{4}{|l|}{ Community inclusion/vocation } \\
\hline Vocational counseling & 59 & 46 & 30 \\
\hline \multicolumn{4}{|l|}{ Employment after discharge } \\
\hline$<10 \%$ & NA & 4 & 65 \\
\hline $11-30 \%$ & NA & 16 & 15 \\
\hline $31-70 \%$ & NA & 27 & 16 \\
\hline$>70 \%$ & NA & 54 & 4 \\
\hline
\end{tabular}

were set up. The LMIC were slow to respond to the needs of the society in this regard. ${ }^{2,5}$ This could be attributed to various reasons. SCI has a comparatively lower incidence as compared to other ailments. Since its management is much more expensive for the same investment, a much larger population can be covered for management of other ailments with more obvious results. ${ }^{5}$

It has been mainly in the past two decades that the LMIC have focused on setting up services for SCI management and dedicated SCI centers. The number of such centers available are, however, often inadequate to meet the needs of the population. ${ }^{3,7}$ In addition, there have been numerous other challenges that have prevented people with SCI in these countries to get the benefits of optimum treatment as per established standards. ${ }^{9}$ These challenges have affected almost all aspects of SCI care. ${ }^{4}$ This study was conducted in order to document these challenges and their impact.

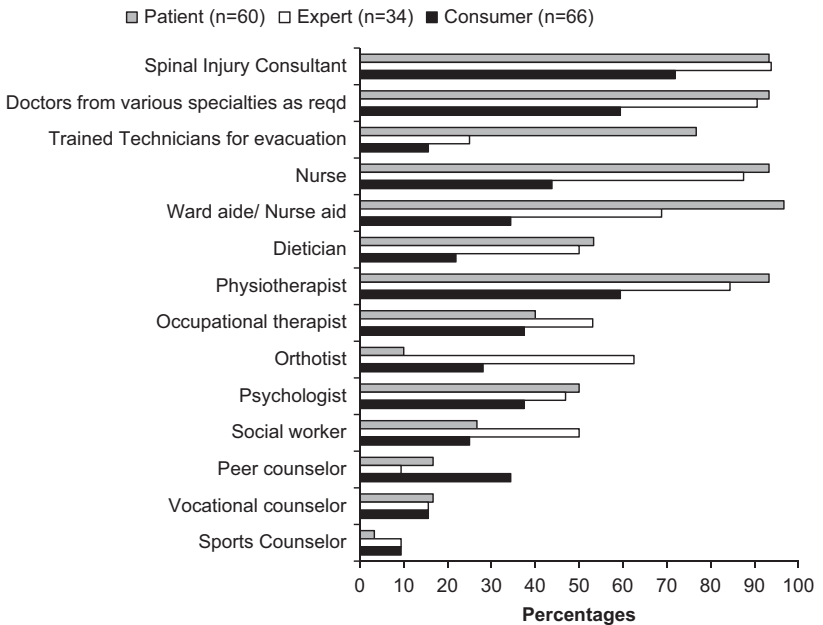

Figure 1 Opinions of respondents regarding availability of various healthcare professionals involved in $\mathrm{SCl}$ management.

Including the experts, patients and consumers in the survey helped in getting a better perspective of the actual prevailing scenario. The potential benefits of consumer involvement in such research is well established. ${ }^{10}$ With lack of adequate information on fulfilled and unfulfilled needs, studies that evaluate consumer perspectives can be useful in obtaining information as to whether or not services are meeting their requirements. It was felt that experts may have a better perception of the facilities available in their institution, especially for acute management, whereas the patients and consumers from their own experience and that of their peers might have a better perception of most other aspects like pre-hospital care, rehabilitation, psychosocial aspects pertaining to management and ease of accessibility of the facilities. In addition, consumers were expected to be in a better position to assess how the outcome translates into practically getting them back into a normal lifestyle and the other issues pertaining to community inclusion.

\section{Pre-hospital care}

It is well established that pre-hospital care substantially improves the outcomes of SCI management. ${ }^{6}$ Implementation of emergency medical services in high-income countries have a positive impact on the chances of survival in people with $\mathrm{SCI}^{13}$ and has decreased the incidence of complete SCI. ${ }^{11}$ Our study brought out that this aspect of SCI management has unfortunately received less attention in the ASCoN region. Only 3\% patient respondents were evacuated by trained staff and 10\% received first-aid at the site of accident. Sixtythree percent of experts reported that pre-hospital care was the most neglected aspect of SCI management. The findings are similar to that of other studies for Asian and other LMIC. ${ }^{4,12-14}$

\section{Institutional transfers}

Studies have also established the importance of minimizing institutional transfers before reaching the definitive institution in achieving an optimal outcome. ${ }^{15}$ Our study revealed that this was far from optimal in the ASCoN region. Sixty-three percent of the patients reported that they reached a definitive institution after two or more institutional transfers.

\section{Delay in initiating treatment}

One of our previous studies ${ }^{3}$ had also indicated that late admission to the definitive institution leads to adverse consequences in people with 


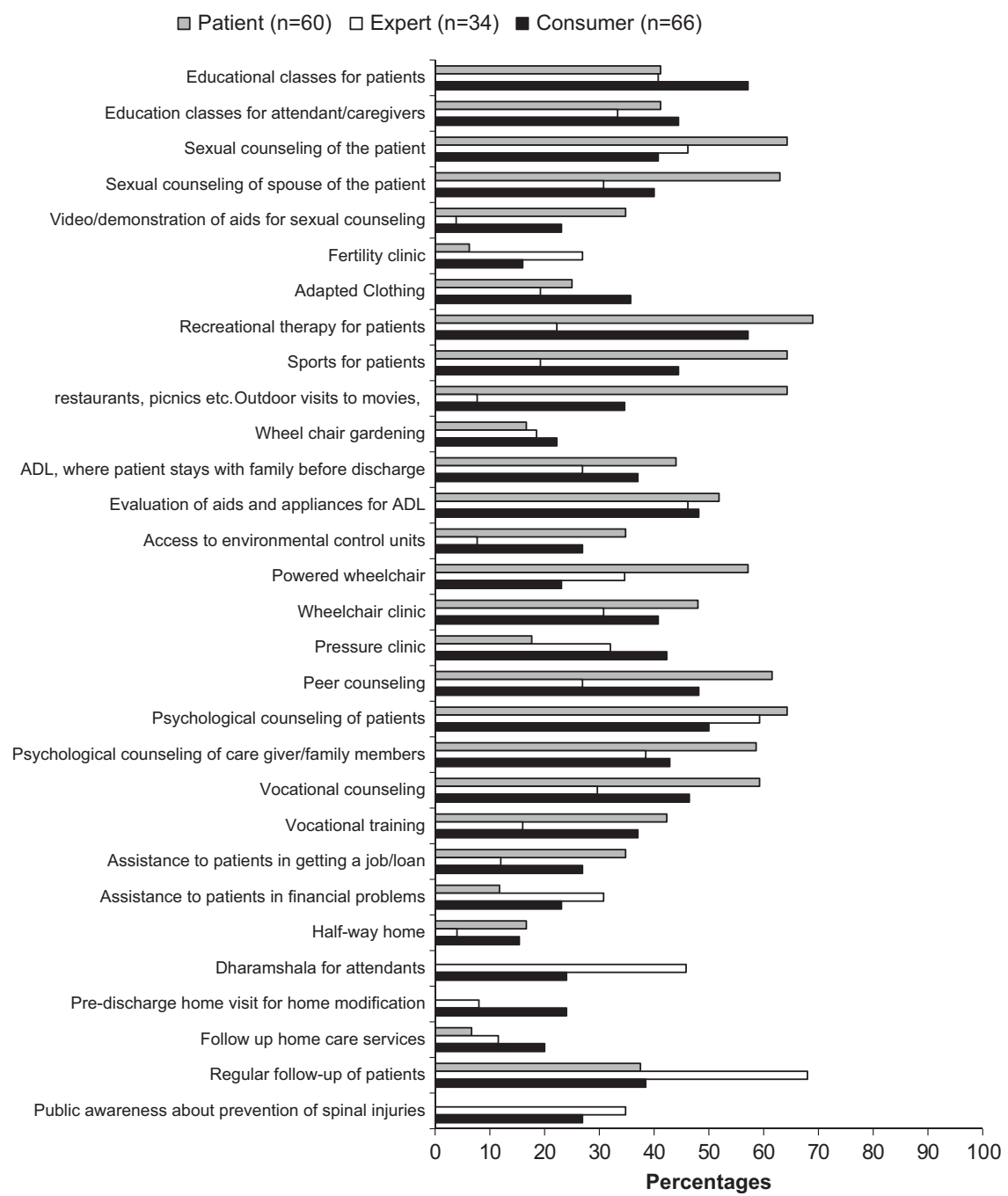

Figure 2 Opinion of respondents regarding availability of facilities for SCl management.

SCI. The compromised outcome of vertebral lesion and rehabilitation, increased incidence and severity of complications led to an overall compromised outcome, longer hospital stay and higher costs of hospitalization. In fact, we had used the terminology of neglected traumatic SCI for people with SCI who reach the definitive institution more than 30 days after the injury. In our study, $22 \%$ of patients took more than 1 month to reach the definitive institution.

\section{Acute hospital care}

Facilities for acute in-hospital care were available in a third of all the facilities. However, acute in-hospital management is not as neglected as the other aspects of SCI management, probably since infrastructure required for acute management generally is almost the same as that for other trauma and is available at most multi-specialty hospitals. In our previous study also, only $10 \%$ of all the neglected traumatic SCI had received no acute management at all, whereas $72 \%$ of patients had been sent home after acute management. ${ }^{3}$

\section{Multidisciplinary rehabilitation}

A multidisciplinary rehabilitation team is required to provide optimal outcome in spinal injured. ${ }^{9}$ Our study brought out that all disciplines are generally not available for SCI management in the ASCoN countries. The findings were similar to that of other studies from ASCoN and other LMIC, where multitasking is often required for care normally provided by other members of the team. ${ }^{5,16,17}$

\section{Comprehensive rehabilitation care}

Comprehensive services of rehabilitation care optimize the outcome, but are generally not available at a large number of facilities in LMIC. ${ }^{4,18}$ This study also reported that important components of comprehensive rehabilitation care like occupational therapy, psychological management, sexuality and fertility management, assistive technology, wheelchair clinic, peer counseling, educational classes, vocational placements, pre-discharge home visit and follow-up homecare services were especially lacking in many of the centers and important principles of rehabilitation like goal planning and monitoring were not followed. For example, $90 \%$ experts felt that the patients do not get the benefit of pre-discharge planning.

\section{Management of neurogenic bladder}

This aspect of management poses a big challenge in the LMIC. Like previous studies bringing out constraints in access to investigations for 
a

$\square$ Patient $\square$ Expert $\square$ Consumer

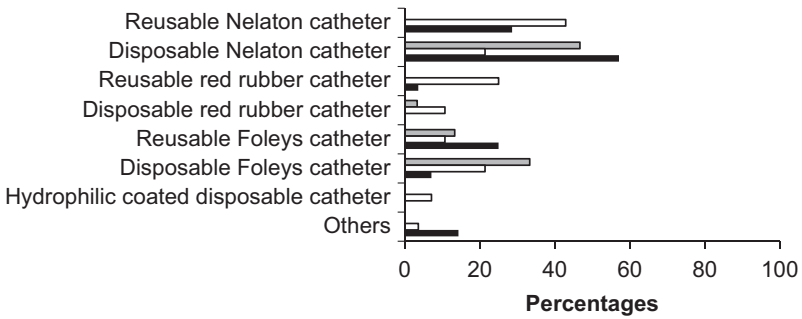

b

$\square$ Patient $\square$ Expert $\boldsymbol{\square}$ Consumer

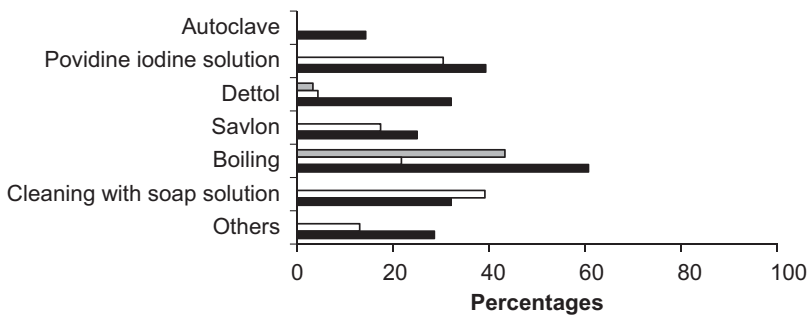

Figure 3 Expert, consumer and patient perspective. (a) Type of catheter used for $\mathrm{CIC}$ and (b) mode of processing reusable catheters.

Table 3 Factors (coded 1 through 9) rated by patients and consumers as 'most important' causes of hindrance of various components of $\mathrm{SCl}$ care

\begin{tabular}{lcc} 
Component of SCl care & Patient & Consumer \\
\hline Pre-hospital care & 1 & 1 \\
Acute management of patients during hospitalization & 1,2 & 1,2 \\
Surgical interventions of patients during hospitalization & $1,2,3$ & $1,2,3$ \\
Bladder management of patients during hospitalization & 1,2 & 1,2 \\
Prevention and management of complications of patients & 1,2 & 1,2 \\
during hospitalization & $1,2,6$ & 1,2 \\
$\begin{array}{l}\text { Comprehensive rehabilitation of patients during } \\
\text { hospitalization }\end{array}$ & 1,9 & $1,2,9$ \\
Sexual rehabilitation of patients during hospitalization & & \\
\hline
\end{tabular}

Codes: 1: Awareness about SCI/illiteracy/inadequate education; 2: Not reaching the definitive institution specializing in management; 3: Financial constraints; 4: Psychological factors; 5: Availability of trained manpower; 6 : Availability of infrastructure (comprehensive rehabilitation facilities); 7: Availability of technology (AT, free hand system, seating clinic); 8: Mind-set and

Social Beliefs; and 9: Inadequate sexual rehabilitation.

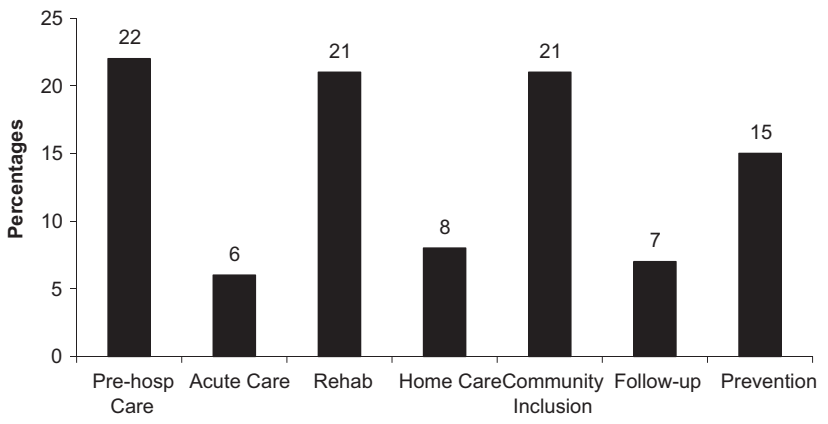

Figure 4 Challenges in management of $\mathrm{SCl}$ in the Indian setup: consumers' perspective.

neurogenic bladder evaluation, ${ }^{19}$ our study also brought out that up to $66 \%$ of patients did not undergo investigations like urodynamics. Knowledge ${ }^{20}$ and access $^{21}$ to simple and cheap methods of urodynamic evaluation are limited.
Table 4 Percentage of respondents declaring factors that help in overcoming the challenges

\begin{tabular}{lccr}
\hline Factors & Patient & Consumer & Expert \\
\hline Strong family support, i.e., joint family system & 93 & 91 & 100 \\
Strong religious beliefs & 23 & 29 & 31 \\
Strong support from the spouse & 13 & 24 & 58 \\
Strong community support & 17 & 48 & 35 \\
Alternative medicine/therapies & 0 & 38 & 4 \\
\hline
\end{tabular}

Unlike other studies from LMIC, where it was found that intermittent catheterization is either not initiated or initiated late, or that patients switched back to an indwelling catheter, our study suggests that people with SCI generally continue to use clean intermittent catheterisation (CIC) for bladder management.

Like in other studies that have brought out that due to the costs involved, the majority of patients in the LMIC are not able to afford disposable catheters, ${ }^{19}$ our study also revealed that the majority of consumers used reusable Nelaton or Foley's catheters (68\%).

Though World Health Organization (WHO) recommends cleaning with soap and running water to process the reusable catheters, ${ }^{22}$ in our study consumers felt that only $32 \%$ of people with SCI use this technique. Various other methods like boiling (61\%), povidone-iodine solution (39\%), dettol (32\%), savlon (25\%) and autoclaving in pressure cooker are the modes of processing commonly used.

WHO recommends use of regularly washed cotton cloth bag for storing of reusable catheters. ${ }^{22}$ As per experts in our study, only $46 \%$ people with SCI do so, whereas many persons still continue to use other improper storing methods like povidone-iodine solution (14\%), savlon (14\%), dettol (9\%) and others (18\%), thus increasing the probability of genito-urinary complications. ${ }^{23}$ The finding of our study that relevant concomitant medications are not adequately used is similar to that of other studies. ${ }^{20}$

Our study also suggested that urinary tract infection is the complication that bothers patients with SCI, the most in the Indian setup. Other studies have also shown that the rate of genito-urinary and renal complications in patients with SCI in LMIC continues to be quite high leading to substantial morbidity and mortality. 3,23

\section{Sexual and fertility counseling}

A large number of consumers (67\%) did not get adequate sexual counseling, and sexual counseling for the spouse was often left out $(78 \%)$ in our study. Very few facilities had access to information brochures or other education material for sexual counseling. The finding was similar to that of other studies, ${ }^{4,19}$ which reveal that sexual counseling and management is one of the most neglected aspects of SCI management in the LMIC. As high as $80 \%$ of people with SCI and $90 \%$ of spouse do not get adequate sexual counseling. ${ }^{24}$ Among the various factors for inadequate emphasis, the prominent ones are lack of awareness and cultural factors, discussion about sex being a taboo especially for females. ${ }^{25}$ Fertility counseling and management are neglected even more. ${ }^{25}$ Our study also brought out that facilities of fertility management are sparse (6\%), and if available, affordability becomes an issue.

\section{Assistive technology}

Our study brought out the challenge posed by the lack of prescribing proper wheelchairs and making suitable assessment. Numerous other studies have also highlighted this issue, ${ }^{6}$ attributing it mainly to affordability despite the availability of low-cost alternatives. ${ }^{26}$ The lack 
of assistive technology services and availability of assistive devices was also brought out. Other studies have also revealed how affordability deprives the spinal injured of these devices, ${ }^{12,26}$ thus affecting their quality of life.

\section{Home-care and follow-up services}

All respondents felt that lack of appropriate home-care services posed a significant challenge for people with SCI. This is unfortunate since home-care services are particularly relevant for LMIC as significant challenges need to be overcome in getting back to a normal lifestyle after discharge, and only few people with SCI can go back to the hospital for a follow-up. The poor follow-up was also substantiated by our study. Sixty percent of the experts felt that less than $50 \%$ of patients came back for a follow-up. This had been mainly attributed in another study to financial constraints, difficulties in access to spinal injury centers and transport infrastructure unsuitable for wheelchair users. $^{5}$

\section{Accessibility, community inclusion and vocation}

The majority of consumers in our study felt that more than $75 \%$ of people with SCI faced problems of access and mobility both in the community and at home. Other studies have also brought out how the issue of accessibility both within the community ${ }^{3}$ and at home ${ }^{7}$ poses a major challenge for people with SCI in the LMIC restricting their mobility substantially.

Consumers of the study were of the opinion that only $10-25 \%$ of people with SCI successfully return to a vocation. Other studies from less high-income countries ${ }^{8,27-29}$ also suggest that return to vocation after SCI is a big challenge. As per experts in our study, inadequate vocational rehabilitation is the main barrier for returning to vocation, followed by lack of awareness of government benefits, lack of opportunity and psychological factors.

\section{Alternative medicine/cellular therapies \\ Although $38 \%$ of consumers in the study felt that the availability of alternative medicine helps overcome the challenges to SCI manage- ment in the Indian setup, this can often work like a double-edged sword. Very often the people with SCI keep pursuing alternative medicine with the hope of a 'cure'. This is especially true for cellular therapies. There had been a media hype about the positive outcome of this therapy. People with SCI often spend precious resources to avail such transplantations. In the meantime they do not pursue rehabilita- tion in the expectation of a 'cure'. Once it becomes evident that they would not improve in neurology, they become depressed.}

\section{Outcomes, morbidity and mortality}

All respondents felt that the outcomes of most SCI in low-income countries are substantially compromised due to the various challenges. The observation is similar to that of other studies. ${ }^{30}$ Cripps et al. ${ }^{31}$ also brought out that, 'LMIC have the highest one-year mortality rates'.

\section{Prevention}

Based on the consumers' perspectives, our study highlighted that the inadequate focus on prevention is one of the biggest challenges in SCI management. A report on global mapping of people with SCI reflects that there is insufficient data on incidence and prevalence. ${ }^{31}$ The absence of accurate data poses a challenge for the formulation of effective prevention programs. Implementation and enforcement of prevention programs is also inadequate, thus compounding the challenge.

\section{Factors contributing to challenges in management}

Consumers and experts indicated that pre-hospital care, physical as well as sexual rehabilitation and home-care services pose the most significant challenge for SCI management in the Indian setup. According to the patients and consumers, lack of awareness about SCI/illiteracy/inadequate education, financial constraints and spinal cord injured not reaching the definitive institution specializing in SCI management were the most important contributing factors hindering different aspects of management during hospitalization. The experts felt that inadequate physical as well as vocational rehabilitation and financial barriers are major factors hindering the integration of spinal injured into the mainstream of society.

Thus, our study provides some insights for experts, healthcare providers and policy makers in India as well as the ASCoN countries on the most significant challenges of SCI management and factors contributing to it. This and other subsequent studies will help in developing strategies to overcome the challenge.

\section{Overcoming the challenge}

The experts, patients and consumers unanimously pointed out that strong family and spouse support are main strengths of society that helps people with SCI overcome the challenge. Strong community support, strong religious beliefs, innovativeness and availability of cheap and abundant manpower were other factors, which had a positive influence in that order of importance.

\section{LIMITATIONS}

On comparison of responses, there were differences of opinion observed between the responses of the patients, consumers and experts. This could be mainly due to the fact that most of the patients were from two tertiary-level centers, which thus had more facilities, whereas the consumers had been treated in all types of centers. The experts were also mainly from tertiary-level centers.

Another limitation of our study was that the patients and consumers were from India, whereas the experts were from many other Asian countries as well. Evaluating patients' and the consumers' perspective from other ASCoN countries would be considered in a subsequent study. And finally, the questionnaire used for this study was not a validated questionnaire. Irrespective of its good face validity, we might have missed some important information related to the challenges in comprehensive management of SCI.

\section{CONCLUSIONS}

SCI in India and in other ASCoN countries face numerous challenges, which affect almost all aspects of comprehensive management. Prehospital care is one of the most neglected components. The number of SCI centers and the services available are often inadequate to meet the needs of the population. Acute care, bladder/bowel care and sexuality as well as fertility management all add to the challenges of SCI management in these countries. There is a higher incidence of complications in LMIC as compared to high-income countries. Facilities for comprehensive rehabilitation are generally not available, and there is a poor concept of multidisciplinary approach. Postdischarge follow-ups, home-care services and community inclusion and vocation are areas in which LMIC lag behind leading to further hindrance in SCI management. Numerous factors like lack of availability of trained manpower, inadequacy and inaccessibility of services, non-availability of multidisciplinary comprehensive care, lack of a barrier-free environment and financial barriers hinder comprehensive management of SCI and contribute to the challenge. Strong family, spouse and community support, positive attitude of the spinal 
cord injured, innovativeness and availability of cheap as well as abundant manpower are the main strengths that help to overcome the challenges of SCI.

\section{DATA ARCHIVING}

There were no data to deposit.

\section{CONFLICT OF INTEREST}

The authors declare no conflict of interest.

\section{ACKNOWLEDGEMENTS}

We extend our gratitude to all the participants from India and the ASCoN region for their support and participation. There is no funding for this study.

1 Donovan WH. Donald Munro Lecture. Spinal cord injury-past, present, and future. J Spinal Cord Med 2007; 30: 85-100.

2 Whalley Hammell K. Quality of life after spinal cord injury: a meta-synthesis of qualitative findings. Spinal Cord 2007; 45: 124-139.

3 Rathore MFA. Spinal Cord Injuries in the Developing World. In: International Encyclopedia of Rehabilitation. Center for International Rehabilitation Research Information and Exchange (CIRRIE)., 2010.

4 Chhabra HS, Arora M. Neglected traumatic spinal cord injuries: causes, consequences and outcomes in an Indian setting. Spinal Cord 2013; 51: 238-244.

5 Rathore MFA, Rashid P, Butt AW, Malik AA, Gill ZA, Haig AJ. Epidemiology of spinal cord injuries in the 2005 Pakistan earthquake. Spinal Cord 2007; 45: 658-663.

6 Pandey V, Nigam V, Goyal TD, Chhabra H. Care of post-traumatic spinal cord injury patients in India: an analysis. Indian J Orthop 2007; 41: 295-299.

7 Scovil CY, Ranabhat MK, Craighead IB, Wee J. Follow-up study of spinal cord injured patients after discharge from inpatient rehabilitation in Nepal in 2007. Spinal Cord 2012; 50: 232-237.

8 Hansen $\mathrm{CH}$, Mahmud I, Bhuiyan AJ. Vocational reintegration of people with spinal cord lesion in Bangladesh - an observational study based on a vocational training project at CRP. Asia Pac Disabil Rehabil J 2007; 18: 63-75.

9 Chiu W-T, Lin H-C, Lam C, Chu S-F, Chiang Y-H, Tsai S-H. Review paper: epidemiology of traumatic spinal cord injury: comparisons between developed and developing countries. Asia Pac J Public Health 2010; 22: 9-18.

10 Nilsen ES, Myrhaug HT, Johansen M, Oliver S, Oxman AD. Methods of consumer involvement in developing healthcare policy and research, clinical practice guidelines and patient information material. Cochrane Database Syst Rev 2006; 3: CD004563.

11 Wyndaele M, Wyndaele J-J. Incidence, prevalence and epidemiology of spinal cord injury: what learns a worldwide literature survey? Spinal Cord 2006; 44: 523-529.

12 Hyun I, Lindvall O, Ährlund-Richter L, Cattaneo E, Cavazzana-Calvo M, Cossu G et al. New ISSCR guidelines underscore major principles for responsible translational stem cell research. Cell Stem Cell 2008; 3: 607-609.
13 Rathore MFA, Hanif S, Farooq F, Ahmad N, Mansoor SN. Traumatic spinal cord injuries at a tertiary care rehabilitation institute in Pakistan. J Pak Med Assoc 2008; 58 53-57.

$14 \mathrm{Ng} \mathrm{HJ}$, Lee LH. Trends in prevalence of deep venous thrombosis among hospitalised patients in an Asian institution. Thromb Haemost 2009; 101: 1095-1099.

15 Halim TA, Chhabra HS, Arora M, Kumar S. Pharmacological prophylaxis for deep vein thrombosis in acute spinal cord injury: an Indian perspective. Spinal Cord 2014; 52 : 547-550.

16 Wells JD, Nicosia S. The effects of multidisciplinary team care for acute spinal cord injury patients. J Am Paraplegia Soc 1993; 16: 23-29.

17 Haig A, Im J, Adewole D, Nelson V, Krabak B. The practice of physical and rehabilitation medicine in sub-Saharan Africa and Antarctica: a white paper or a black mark? J Rehabil Med 2009; 41: 401-405.

18 Rathore FA. Neglected traumatic spinal cord injuries: experience sharing from Pakistan. Spinal Cord 2013; 51: 652-653.

19 Linsenmeyer TA, Linsenmeyer MA. Impact of annual urodynamic evaluations on guiding bladder management in individuals with spinal cord injuries. J Spinal Cord Med 2013; 36: 420-426.

20 Mikhail JN, Harris YD, Sorensen VJ. Injury severity scoring: influence of trauma surgeon involvement on accuracy. J Trauma Nurs 10: 43-47.

21 Wyndaele JJ, Kovindha A, Madersbacher H, Radziszewski P, Ruffion A, Schurch B et al. Neurologic urinary incontinence. Neurourol Urodyn 2010; 29: 159-164.

22 Promoting Independence Following a Spinal Cord Injury. A Manual for Mid-Level Rehabilitation Workers (WHO/RHB/96.4). WHO: Geneva, Switzerland, 1996.

23 Whiteneck GG, Charlifue SW, Frankel HL, Fraser MH, Gardner BP, Gerhart KA et al. Mortality, morbidity, and psychosocial outcomes of persons spinal cord injured more than 20 years ago. Paraplegia 1992; 30: 617-630.

24 Sharma SC, Singh R, Dogra R, Gupta SS. Assessment of sexual functions after spinal cord injury in Indian patients. Int J Rehabil Res 2006; 29: 17-25.

25 White MJ, Rintala DH, Hart KA, Fuhrer MJ. Sexual activities, concerns and interests of women with spinal cord injury living in the community. Am J Phys Med Rehabil 1993; 72: 372-378.

26 Hunt PC, Boninger ML, Cooper RA, Zafonte RD, Fitzgerald SG, Schmeler MR. demographic and socioeconomic factors associated with disparity in wheelchair customizability among people with traumatic spinal cord injury. Arch Phys Med Rehabil 2004; 85: 1859-1864.

27 Owen T, Halliday J, Stone C. Neural tube defects in Victoria, Australia: potential contributing factors and public health implications. Aust N Z J Public Health 2000; 24: 584-589.

28 Samuelkamaleshkumar S, Radhika S, Cherian B. Community reintegration in rehabilitated South Indian persons with spinal cord injury. Arch Phys 2010; 91: 1117-1121.

29 Kassah A. Begging as work: A study of people with mobility difficulties in Accra, Ghana. Disabil Soc 2008; 23: 163-170.

30 Nwadinigwe CU, Iloabuchi TC, Nwabude IA. Traumatic spinal cord injuries (SCI): a study of 104 cases. Niger J Med 2004; 13: 161-165.

31 Lee BB, Cripps RA, Fitzharris M, Wing PC. The global map for traumatic spinal cord injury epidemiology: update 2011, global incidence rate. Spinal Cord 2014; 52 $110-116$.

Supplementary Information accompanies this paper on the Spinal Cord website (http://www.nature.com/sc) 